\title{
Relationship between P-wave dispersion, left ventricular mass index and blood pressure
}

\author{
Elibet Chávez, M.D., ${ }^{a}$ Emilio González, M.D., ${ }^{b}$ María del C. Llanes, M.D. ${ }^{c}$ \\ Merlin Gari, M.D., ${ }^{c}$ Yosvany García ${ }^{c}$ M.D. and Julieta García Sáez, M.D. ${ }^{d}$
}

\begin{abstract}
Introduction. The study of arterial hypertension risk factors in children guarantees the establishment of health policies to avoid complications associated with this illness in the future. The highest values of P-wave dispersion during sinus rhythm are pointed as predictors of atrial fibrillation in adulthood since there is an association between arterial hypertension, $\mathrm{P}$-wave dispersion and left ventricular hypertrophy.

The aim of this study was to determine the relationship between blood pressure, left ventricular mass index and $\mathrm{P}$-wave dispersion in the pediatric population.

Population and methods. In the frame of the PROCDEC II project, children from 8 to 11 years old, without known heart conditions were studied. Arterial blood pressure was measured in all the children; a 12-lead surface ECG and an echocardiogram were done as well.

Results. Left ventricular mass index mean values for normotensive $\left(25.21 \pm 5.96 \mathrm{~g} / \mathrm{m}^{2}\right)$ and hypertensive $\left(30.38 \pm 7.39 \mathrm{~g} / \mathrm{m}^{2}\right)$ children showed significant differences $(p=0.000)$. The mean value of the left atrial area was significantly different $(p=0.000)$ when comparing prehypertensive $(10.98 \pm 2.23 \mathrm{~cm} 2)$ and hypertensive $(12.21 \pm$ $\left.1.27 \mathrm{~cm}^{2}\right)$ children to normotensive ones $(10.66$ $\left.\pm 2.38 \mathrm{~cm}^{2}\right)$. The correlation of $\mathrm{P}$-wave dispersion and the left ventricular mass index showed an $\mathrm{r}=0.87$ and $\mathrm{p}=0.000$.

Conclusions. P-wave dispersion is increased in pre- and hypertensive children compared to normotensive ones. A dependence of the P-wave dispersion of the left ventricular mass index was found in hypertensive children.
\end{abstract}

Key words: Left ventricular mass index, P-wave dispersion, prevention.

http:/ /dx.doi.org/10.5546/aap.2013.206

\section{INTRODUCTION}

When the impulse is generated in PROCDEC II (Asturias/ Cuba) Project for the detection and management of high blood pressure in children. The Cuban side is represented by Universidad Martha Abreu de las Villas.

Received: $11-8-12$ Accepted: 1-23-13 described normal atrial activation pattern produces the normal $\mathrm{P}$-wave in the ECG. This wave lasts between 0.07 and 0.11 seconds; the first part of this period corresponds to the right atrial depolarization while the second to the left atrial depolarization. When there are anatomical and functional alterations of the excitation conducting structures and atrial wall, at the time the stimulus spreads out along the atria there are modifications in the P-wave of the electrocardiogram (ECG); mainly, there is an increase in the duration of this wave. ${ }^{1,2}$

Atrial dilation and interstitial fibrosis have been recognized in the so called atrial remodeling. In these mechanisms the renin-angiotensinaldosterone system, already known in the pathophysiology of arterial hypertension $(\mathrm{AH})$, takes part with a profibrotic role of angiotensin II. Reversion of atrial remodeling has been accomplished with angiotensin converting enzyme inhibitors and with angiotensin II receptor blockers. ${ }^{3-5}$ There is a significant relationship between $\mathrm{AH}, \mathrm{P}$-wave dispersion associated with atrial fibrillation and left ventricular hypertrophy. ${ }^{6}$

In the light of the current knowledge we could formulate the following hypothesis: The highest $\mathrm{P}$-wave dispersion values will be found in patients with a high risk of having $\mathrm{AH}$ (prehypertensives) and in pediatric hypertensives versus the values proposed for normotensives, ${ }^{7}$ and it is also expected to additionally find children with a normal left ventricular mass index and an increased P-wave dispersion.

Knowing the relationship described in adults between arterial blood pressure, left ventricular mass 
index and P-wave dispersion, we consider it is necessary to determine these relationships in the pediatric population.

\section{POPULATION AND METHODS}

This study which was developed as part of the PROCDEC II Asturias-Cuba project for the diagnosis and management of arterial hypertension in the pediatric population was conducted by a multidisciplinary team (pediatricians, cardiologists, pediatric cardiologists, endocrinologists and Clinical Laboratory and Statistics and IT specialists). A total of 5025 children between 8 and 11 years old from 43 primary schools of Santa Clara district, province of Villa Clara, Cuba, were included. A detailed medical history was obtained from all the children as well as complementary studies that helped in the diagnosis of essential and secondary arterial hypertension and other comorbidities (diabetes mellitus, blood disorders, kidney and adrenal diseases, hypertrophic cardiomyopathy).

A cluster sampling was done in the present study. Schools involved were randomly selected; the number of children selected for this age group totaled 720. Children studied were attending the third, fourth and fifth grade of school courses 2009-2010 and 2010-2011 at three primary schools in the urban area.

Inclusion criteria were:

- Children between 8 and 11 years old.

- Sexual development in stage 1 of Tanner, considered in a prepubertal stage on which sexual hormones still do not have an impact.

- Children's consent.

- Parents' or tutors' consent for children's participation in the study.

Exclusion criteria comprised:

- Children younger than 8 years old in whom psychological studies showed greater fear or stress when in front of the medical staff.

- Congenital heart disease as the child's personal history or diagnosed during the study.

- Secondary arterial hypertension.

- Other comorbidities: diabetes mellitus, blood disorders, kidney and adrenal diseases.

- Idiopathic hypertrophic cardiomyopathy.

A cross sectional study was done with the selected sample.

Height was measured in meters using a height rod specifically designed for this aim, children had to be barefoot.
Arterial blood pressure was measured with the standard method, with a calibrated oscillometric sphygmomanometer and fit seal, always measured by the same staff, under the same conditions, using cuffs of a size adequate to the arm circumference and a pediatric stethoscope. ${ }^{8}$ Cuffs of $7.5 \mathrm{~cm}$ designed for children with an arm circumference of up to $18.5 \mathrm{~cm}$ and $9 \mathrm{~cm}$ when the circumference was 18.6 to $22.5 \mathrm{~cm}$.

Blood pressure was taken in the right arm resting on a table after 10 minutes of being in a relaxed position. The cuff, without wrinkles, was positioned approximately at the height of the heart. The cuff was inflated $20 \mathrm{mmHg}$ above the level of the abolished radial pulse and it was descended at an approximate rate of $2 \mathrm{mmHg}$ per second. Systolic blood pressure was recorded at the moment of hearing the first arterial sound or Korotkoff phase I sound while the diastolic blood pressure was recorded at the time of hearing a change or the abolishment of the arterial sound tone or Korotkoff phase IV. ${ }^{9,10}$ Four readings were done.

The group of selected schoolchildren had had their blood pressure measured a few times so, before starting with the study measurements, children first became familiarized with this technique by watching cartoons about arterial hypertension. Psychologists indicated the precise time to start the study once they were sure that the presence of the medical team would cause no stress nor fear related psychosomatic disturbances to the participants.

Children were classified as normotensive (blood pressure below the $90^{\text {th }}$ percentile for age, gender and height), prehypertensive (between the $90^{\text {th }}$ and $95^{\text {th }}$ percentiles) and hypertensive (above the $95^{\text {th }}$ percentile). ${ }^{9}$

A 12-lead surface electrocardiogram was performed with a Nyhom Kodem equipment standardized at $50 \mathrm{~mm} /$ second paper speed. $\mathrm{P}$-waves were measured on each lead. The maximum $P$ value was taken as the highest measured $\mathrm{P}$-wave value; the minimum $\mathrm{P}$ value was the lowest measured value and P-wave dispersion was the difference between the maximum $P$ value and the minimum $P$ value.

The P-wave was measured manually, taking the first positive, negative or isodiphasic wave of the electrocardiogram which precedes the QRS complex measuring it at the beginning of its deflection (positive or negative) in the isoelectric line up to its termination in the same line. A magnifying glass and a ruler was used to this aim, 
with the recording of measures as 1 unit as equal to 25 milliseconds (ms). The value of the reading, done by two experts, was taken into consideration when it was coincident; when there was no coincidence a third expert, unaware of the already measured values, participated; finally the value coinciding between two out of the three readings was considered and entered in the database. The mean value and standard deviation for the $P$ dispersion measured by them was calculated for each observer.

When none of the three readings coincided, two of the closest values measured were considered. The difference between these two chosen values did not go beyond the subtraction between standard deviations for the P-wave dispersion mean calculated for each observer, taking the lowest measured value between these observers. It was possible to be done when there were differences among the observers provided this difference was not above $2 \mathrm{~ms}$. No reading was left out of the study.

ECGs with 10 or more leads, with measurable $\mathrm{P}$-waves were considered for the study, according to what is established for the $\mathrm{P}$-wave measurement and the calculation of its dispersion. ${ }^{11}$ No measured electrocardiogram was excluded.

The ECG was done with a $3.5 \mathrm{MHz}$ Aloka 5000 probe to get the following outcome measures: left ventricle in diastole, left ventricle in systole, interventricular septum thickness and posterior wall thickness.

The left ventricular mass was calculated in grams, according to what Deveroux, et al. proposed. $^{12}$

Left ventricular mass $(\mathrm{LVM})=1.04 \mathrm{x}([\mathrm{LVIDD}$ + PWTD + IVSTD]3- [LVIDD]3) - 13.6 g, in grams.

Where LVIDD: left ventricular internal diameter in diastole; PWTD: posterior wall thickness in diastole; IVSTD: interventricular septum thickness in diastole.

The left ventricular mass index (LVMI) was estimated; the reviewed authors considered the 95th percentile as the normal value $\left(38.6 \mathrm{~g} / \mathrm{m}^{2}\right){ }^{7}$ Though reference data were estimated based on relatively small cohorts, there are no prospective data and in the few studies available different criteria have been used. ${ }^{10,13}$

Formula: $\mathrm{LVMI}=\mathrm{LVM} /$ height $^{2.7}$

The left atrial area was measured by mapping the inner border of the atrial endocardium, synchronized with the electrocardiogram on the TP segment.

\section{Ethical aspects}

The approval was requested to the Ethics Committees of Universidad Martha Abreu de las Villas and of Hospital Pediátrico Universitario José Luis Miranda. Before their approval, those from the Ministries of Health and Education were requested; they were received in March 2007. The informed consent was requested to the parents, and children who participated in the study gave their approval.

\section{Statistical analysis}

The SPSS 17.0 software was used to analyze data expressed as mean and standard deviation. Tests for homogeneity (one-way ANOVA) and of sample normalization were done and highly significant statistical results $(p=0.000)$ were found and therefore parametric data analyses were carried out. Comparisons of means among the diagnostic groups (normotensive, prehypertensive and hypertensive) were done based on the variance analysis using a dependent ( $P$-wave dispersion, left ventricular mass index, atrial area, as appropriate) and independent (diagnosis) outcome measure, and when these provided $\mathrm{p}=0.000$ multiple, post hoc comparisons were done with Scheffé. The linear correlation test for the two main outcome measures (P-wave dispersion and LVMI) of the study was done.

\section{RESULTS}

Five hundred and sixty five children were eligible. Two were excluded because of lack of consent, 1 because of a corrected heart disease and 1 because of an accessory pathway. Forty six out of the 561 children included were removed because the echocardiogram studies had not been completed.

The mean of the P-wave dispersion according to the diagnoses was distributed as shown on Table 1: $31.85 \mathrm{~ms}$, normotensive; $37.33 \mathrm{~ms}$, prehypertensive; $39.74 \mathrm{~ms}$, hypertensive, with significant differences for these mean values between normotensives and prehypertensives $(p=0.000)$ and between normotensive and hypertensive $(p=0.000)$, but this was not the case between prehypertensives and hypertensives $(p=$ 0.411).

The comparison of LVMI mean shows significant differences between normotensives and hypertensives $(p=0.000)$, and between normotensives and prehypertensives $(p=0.000)$. There were no significant differences between prehypertensives and hypertensives $(p=0.07)$. 
The left atrial area is larger for hypertensives versus normotensives $\left(12.21 \mathrm{~cm}^{2}\right.$ and $10.66 \mathrm{~cm}^{2}$, respectively, $\mathrm{p}=0.002$ ).

Blood pressure values show that the mean is higher for diastolic and systolic values in hypertensives versus prehypertensives and normotensives.

When observing that the P-wave dispersion and LVMI were higher for hypertensive children, a linear correlation (after the partial correlation weight and height adjusted, $p=0.000$ ) was done between these two variables considering $\mathrm{P}$-wave dispersion as dependent (Figure 1); $\mathrm{r}=0.87$ and $\mathrm{p}=0.000$.

The relationship of children with a normal LVMI and an increased P-wave dispersion and of children with an increased LVMI and an increased $\mathrm{P}$-wave dispersion is shown on Table 2. The number of children with an increased LVMI and increased P-wave dispersion is higher, regardless of the diagnosis: 72 versus 57 normotensive children, 56 versus 42 prehypertensive children and 11 versus 4 hypertensive children.

\section{DISCUSSION}

There is a high percentage of prehypertensive children $(30.29 \%)$ who, when adding hypertensive children $(5.04 \%)$, reach $35.33 \%$ of patients with high values of blood pressure. Studies about arterial hypertension in childhood and adolescence have led to the identification of a marker for future cardiovascular disease; this is particularly relevant in areas with a high rate of CV disease. ${ }^{14-15}$ Children whose blood pressure values are between the $90^{\text {th }}$ and $95^{\text {th }}$ percentiles

FIGURE 1. Linear correlation between the left ventricular mass index and P-wave dispersion in hypertensive children

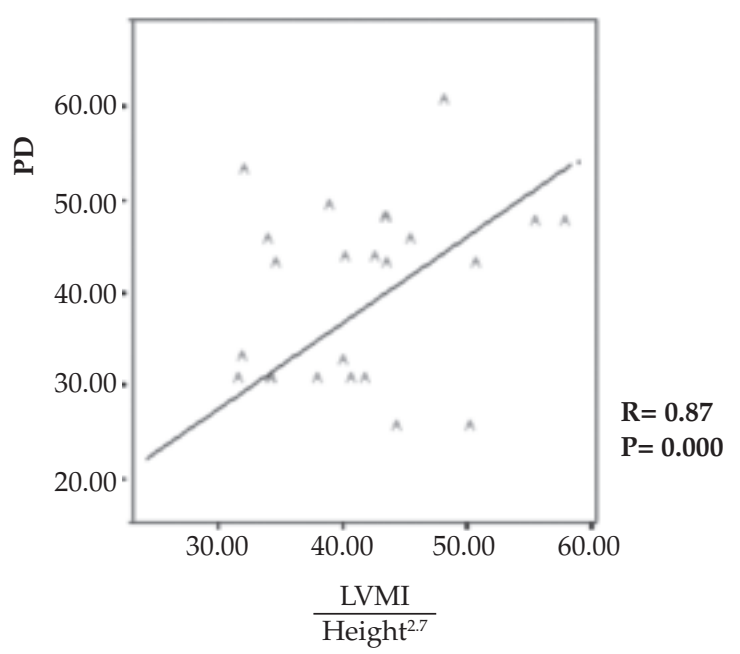

PD: P-wave dispersion.

LVMI . left ventricular mass index adjusted for the height Height $^{2.7}$ elevated to the 2.7.

TABLE 1. Distribution of mean and standard deviation values for blood pressure, P-wave dispersion, left ventricular mass index and left atrial area

\begin{tabular}{|c|c|c|c|c|}
\hline $\begin{array}{l}\text { Group } \\
\mathrm{n}(\%)\end{array}$ & $\begin{array}{c}\text { Normotensive } \\
333(64.66)\end{array}$ & $\begin{array}{c}\text { Prehypertensive } \\
156(30.29)\end{array}$ & $\begin{array}{c}\text { Hypertensive } \\
26(5.04)\end{array}$ & $p$-value \\
\hline $\begin{array}{l}\text { Mean systolic BP } \\
\text { Minimum-maximum }\end{array}$ & $\begin{array}{l}108.97 \mathrm{mmHg} \\
88-135 \mathrm{mmHg}\end{array}$ & $\begin{array}{l}115.41 \mathrm{mmHg} \\
95-135 \mathrm{mmHg}\end{array}$ & $\begin{array}{l}119.98 \mathrm{mmHg} \\
95-140 \mathrm{mmHg}\end{array}$ & $\begin{array}{c}\text { Normo/prehyper } \mathrm{p}=0.000 \\
\text { Normo } / \text { hyper } \mathrm{p}=0.000 \\
\text { Prehyper } / \text { hyper } \mathrm{p}=0.000\end{array}$ \\
\hline $\begin{array}{l}\text { Mean diastolic BP } \\
\text { Minimum-maximum }\end{array}$ & $\begin{array}{l}65.74 \mathrm{mmHg} \\
53-84 \mathrm{mmHg}\end{array}$ & $\begin{array}{l}73.45 \mathrm{mmHg} \\
65-85 \mathrm{mmHg}\end{array}$ & $\begin{array}{l}75.58 \mathrm{mmHg} \\
65-90 \mathrm{mmHg}\end{array}$ & $\begin{array}{c}\text { Normo/prehyper } \mathrm{p}=0.000 \\
\text { Normo } / \text { hyper } \mathrm{p}=0.000 \\
\text { Prehyper } / \text { hyper } \mathrm{p}=0.000\end{array}$ \\
\hline $\begin{array}{l}\text { P-wave dispersion } \\
\text { Mean } \pm \mathrm{SD}(\mathrm{ms})\end{array}$ & $31.85 \pm 9.30$ & $37.33 \pm 9.37$ & $39.74 \pm 11.59$ & $\begin{array}{c}\text { Normo/prehyper } \mathrm{p}=0.000 \\
\text { Normo/hyper } \mathrm{p}=0.000 \\
\text { Prehyper } / \text { hyper } \mathrm{p}=0.411\end{array}$ \\
\hline $\begin{array}{l}\text { LVMI } \\
\text { Mean } \pm \text { SD }\left(\mathrm{cm}^{2}\right)\end{array}$ & $25.21 \pm 5.96$ & $27.98 \pm 8.40$ & $30.38 \pm 7.39$ & $\begin{array}{c}\text { Normo/prehyper } \mathrm{p}=0.000 \\
\text { Normo/hyper } \mathrm{p}=0.0000 \\
\text { Prehyper } / \text { hyper } \mathrm{p}=0.07\end{array}$ \\
\hline $\begin{array}{l}\text { LAA } \\
\text { Mean } \pm \mathrm{SD}\left(\mathrm{cm}^{2}\right)\end{array}$ & $10.66 \pm 2.38$ & $10.98 \pm 2.23$ & $12.21 \pm 1.27$ & $\begin{array}{c}\text { Normo/prehyper } \mathrm{p}=0.000 \\
\text { Normo/hyper } \mathrm{p}=0.000 \\
\text { Prehyper } / \text { hyper } \mathrm{p}=0.411\end{array}$ \\
\hline
\end{tabular}

Variance analysis (one-way ANOVA) with multiple post hoc comparisons. Scheffé.

BP: blood pressure; LVMI: left ventricular mass index; LAA: left atrial area; SD: standard deviation. 
are at risk of suffering frank hypertension if there is not an adequate intervention in place. ${ }^{16}$ Studies in Argentina report a similar percentage of hypertensive adolescents ( $4 \%$ to $5.1 \%$ ) and a much lower rate of prehypertensive adolescents $(16.8 \%$ to $17 \%) .{ }^{17,18}$ We believe that the influence of poor dietary habits ("junk food") and sedentarism due to passive games - which has grown a lot in Argentina in the latest three to four yearsmight be having an impact on the number of prehypertensives in the present study.

In adults, it has been shown that there is a relationship between the highest values of P-wave dispersion and the development of paroxysmal atrial fibrillation because of the atrial wall electrophysiological abnormalities. The highest values of the P-wave dispersion show longer intra- and interatrial conduction times which speaks in favor of the presence of electrical heterogeneity at this anatomical level. ${ }^{19,20}$

The early diagnosis of arterial hypertension together with the onset of a timely treatment in these children would reduce the disease related cardiovascular risk. Additionally, it has been shown that hypertension treatment normalizes P-wave dispersion values. ${ }^{21,22}$ The management of arterial hypertension from childhood would prevent or delay the damage to target organs.

In multivariable models, established cardiovascular disease, arterial hypertension, age and left ventricular hypertrophy have a stronger association with atrial fibrillation. ${ }^{23,24}$ Ciaroni, et al. found an association between the increased P-wave dispersion and atrial fibrillation. Reviewed studies on adults that mention this relationship describe an atrial electromechanical and anatomical remodeling due to the damage caused by sustained hypertension.

In our study, in children with newly diagnosed essential hypertension, LVMI was found to be increased in hypertensive children, with significant differences in the mean value between normotensive and hypertensive children (See Table 1) and a positive correlation between the P-wave dispersion and the LVMI in hypertensive children (See Figure 1), relationship which has already been described in adults.

The LVMI is one of the outcome measures related to the highest values of $\mathrm{P}$-wave dispersion. However, as it can be seen in Table 2, there are children with a normal LVMI with an increase in P-wave dispersion. According to our judgment, what we first have to explain is that the highest values of P-wave dispersion not only depend on the left ventricular mass and on the presence of hypertension because there is a group of normotensive children $(17.11 \%)$ that have a normal LVMI and an increased P-wave dispersion, and this would account for the normal patterns and interatrial conduction blocks of this subpopulation.

There are other clinical and paraclinical conditions that prolong P-wave dispersion, such as age and obesity, ${ }^{26}$ but it is worth mentioning that in our study, statistical tests were adjusted to weight, age and height to avoid the influence of these variables. However, when adding prehypertensive and hypertensive clinical conditions ( 46 children [25.27\%] out of 182) to children with a normal LVMI, they outnumber normotensive children. The latter shows a direct relationship between increased blood pressure readings and the higher values of P-wave dispersion since childhood. ${ }^{27-29}$

Much has been described about the presence of anatomical disorders together with atrial electrophysiological abnormalities. ${ }^{3}$ However, findings in this study, where children with a normal LVMI and increased P-wave dispersion are observed, support the new theory that intraand interatrial conduction disorders expressed by the increased $\mathrm{P}$-wave dispersion in structurally

TABLE 2. Relationship of children with normal left ventricular mass index and increased P-wave dispersion and children with increased left ventricular mass index and increased P-wave dispersion

\begin{tabular}{lccccc}
\hline Outcome measures & \multicolumn{2}{c}{$\begin{array}{c}\text { Normal LVMI } \\
\text { and increased PD }\end{array}$} & \multicolumn{2}{c}{$\begin{array}{c}\text { Increased LVMI } \\
\text { and increased PD }\end{array}$} & $p$-value \\
\cline { 2 - 5 } & No & $\%$ & No & \% & 0.000 \\
\hline Normotensive $(n$ 333) & 57 & 17.11 & 72 & 21.62 & 0.000 \\
Prehypertensive $(n$ 156) & 42 & 26.92 & 56 & 35.89 & 0.000 \\
Hypertensive $(n$ 26) & 4 & 15.38 & 11 & 42.30 & \\
\hline
\end{tabular}

No: number of children; LVMI: left ventricular mass index; PD: P-wave dispersion. 
healthy hearts are present before anatomical disturbances, as stated by Martín García, et al. ${ }^{30}$ Taking this into account, blood pressure measurements in pediatrics and the management of prehypertensive and hypertensive children should be part of routine physical examinations to prevent atrial wall electrophysiological changes at an early stage.

Table 2 shows the superiority in the number of children with an increased LVMI (the presence of hypertrophic cardiomyopathy was ruled out based on diagnostic criteria) and an increased P-wave dispersion; this relationship found in our sample is similar to that found in adults. ${ }^{7}$ Besides, this condition (increased LVMI and P-wave dispersion) has a similar pattern to that already explained (normal LVMI and increased P-wave dispersion); i.e., blood pressure has an impact on P-wave dispersion given that the number of normotensive children $(21.62 \%)$ is lower than the sum of prehypertensive and hypertensive groups (67 children [35.81\%] out of 182).

The left atrial area can be increased due to the systemic pressure overloads. A previous pediatric study ${ }^{31}$ shows higher values in the left atrial area in hypertensive children compared to normotensive children as well as a significant linear relationship between $\mathrm{P}$-wave dispersion and the left atrial area in hypertensive children.

Strengths of the study: The study of P-wave electrophysiological characteristics was conducted using a sample of the PROCDEC II project designed with a multidisciplinary approach that favors knowledge integration for the diagnosis and management of arterial hypertension in pediatrics.

Weaknesses of the study: This is a sample of schoolchildren of an urban area that might not be representative of all the children of the same age in other urban, suburban and rural regions of Cuba.

\section{CONCLUSIONS}

LVMI and P-wave dispersion are higher in prehypertensive and hypertensive patients compared to normotensive ones. There were prehypertensive and hypertensive patients with a normal LVMI and an increased P-wave dispersion.

\section{Acknowledgments}

To PROCDEC II project (Asturias/Cuba) for the detection and management of arterial hypertension in children. To Hospitals Celestino Hernández Robau and Cardiocentro Ernesto
Che Guevara for their support as far as the equipment.

\section{REFERENCES}

1. Gunduz H, Binak E, Arinc H, Akdemir R, Ozhan H et al. The relationship between $\mathrm{P}$ wave dispersion and diastolic dysfunction. Tex Heart Inst J 2005; 32:163-7.

2. Wang C, Xie ZW, Li MX. Analysis of P interval dispersion and its correlative factors among Chinese. Hunan Yi Ke Da Xиe Xue Bao 2001 Jun 28; 26(3):241-3.

3. Chávez González E, Castro Hevia J, González Rodríguez E. Dispersión de la Onda Pen el Electrocardiograma con Bases en el Potencial de Acción Auricular y en la Heterogeneidad del Impulso en Aurículas. Relampa 2010; 23(3):126-33.

4. Fuster et al. ACC/AHA/ESC 2006 Guidelines for the Management of Patients With Atrial Fibrillation. JACC 2006; 48(4):854-906.

5. Anter E, Callans DJ. Pharmacological and Electrical Conversion of Atrial Fibrillation to Sinus Rhythm Is Worth the Effort. Circulation 2009;120:1436-43.

6. Lombardi F. Inhibidores ECA y FA. 3er Simposio internacional de fibrilación auricular por internet. [Internet series]. Oct 1-Oct30,2009 [accessed on 10-08-2009: [approx. 3p]. Available at: http:/ / www.af-symposium.org

7. Köse S, Aytemir K, Sade E, Can I, et al. Detection of patients with hypertrophic cardiomyopathy at risk for paroxysmal atrial fibrillation during sinus rhythm by P-wave dispersión. Clinical Cardiology 2006;26(9):431-4.

8. Chávez González E, Castro Hevia J, González Rodríguez E, Llanes Camacho MC et al. Dispersión de la Onda P, Criterios de Normalidad para una Población Pediátrica Cubana. Relampa 2012;25(1):13-19.

9. The Fourth Report on the Diagnosis, Evaluation, and Treatment of High Blood Pressure in Children and Adolescents. Pediatrics 2004; 114: 555-76.

10. Lurbe E, Cifkova R, Cruickshank JK, Dillon MJ, et al. Manejo de la hipertensión arterial en niños y adolescentes: Recomendaciones de la Sociedad Europea de Hipertensión. Hipertens Riesgo Vasc 2010; 27 (2): 47-74.

11. Dilaveris P, Stefanadis Ch. Dispersión de la onda P: marcador no invasivo valioso de vulnerabilidad a la fibrilación auricular. The 2nd ISHNE atrial fibrillation worldwide internet symposium. [Internet series]. April 1 - April 30, 2007 [accessed on 01-05-2009: [approx. 3p]. Available at: http://www.af-symposium.org

12. DevereuxRB, ReicheckN.Echocardiographicdetermination of left ventricular mass in man. Anatomic validation of the method. Circulation 1977; 55: 613-618.

13. Ruiz Pons M. Repercusiones cardiovasculares de la obesidad infantil. Mesa redonda Obesidad Infantil. Rev Can Ped 2009; 33 (2): 115-19.

14. Hayman L, Williams Ch. Hypertension and obesity in youth (AHOY). Circulation 2004; 10:226.

15. Walker D, Mc. Carron P. Trends in blood pressure over 10 years in adolescent. BMJ 2004; 329:139.

16. Philippe Baguet J, Erdine S, Mallion JM. Hypertensión and arrhythmia. European society of hypertension scientific newsletter: Update on hypertension management. 2005; 6(24).

17. Cangas García SR, Hernández García S, García Martínez A, Prat Ribet I et al. Pesquisaje de hipertensión arterial en los adolescentes. Rev. Ciencias Médicas enero-marzo, 2011; 15(1):103-15.

18. Rodríguez Ortiz N, Planelles Suarez Y. Comportamiento de la hipertensión arterial en adolescentes. Jagüey grande, Matanzas. [Internet series]. 2012 [accessed on 01-20-2013: [approx. 3p]. Available at: http://monografias.umcc.cu/ 
monos/2012/FUM\%20Jaguey\%20Grande/mo12212.pdf

19. Hatziyiann A, Tsioufis K, Kallikazaros J, Stefanadis $\mathrm{CH}$. P-wave dispersion evaluated on ecg or 24h-ECG is a predictor of paroxysmal atrial fibrillation in essential hypertension. Rev Am J Hypertens 2004: (17):149A-150A.

20. Fibrilación auricular e hipertensión arterial. Pág Web. [Internet series]. 2005 marz. [Available at: http:/ /www. seh-lelha.org/club/cuestion43.htm] [Consulta: 5 enero de 2009]. [approx. 3p]

21. Tuncer M, Fettser DV, Gunes Y, Batyraliev TA, et al. Comparison of effects of nebivolol and atenolol on P-wave dispersion in patients with hypertension. Kardiologiia 2008;48(4):42-5.

22. Celik T, Iyisoy A, Kursaklioglu H, Yilmaz MI, et al. Telmisartan has a much greater lowering effecton PWD and Pmaximum values than ramipril. Clin Cardiol 2005;28(6):298-302.

23. Celik T, Cagdas Yuksel U, Bugan B, Celik M, et al. P-Wave Dispersion and Its Relationship to Aortic Elasticity in Young Prehypertensive Patients. Am J of Hypertens 2009;12(22):1270-5.

24. Cea-Calvo L, Redón J, Lozano JV, Fernández Pérez C, et al. Prevalencia de fibrilación auricular en la población española de 60 o más años de edad. Estudio PREV-ICTUS. Rev Esp Cardiol 2007; 60:616-624.

25. CiaroniS, Cuenoud L, Bloch A. Clinical study to investigate the predictive parameters for the onset of atrial fibrillation in patients with essential hypertension. Am heart J 2000 May; 139(5):814-9.

26. Chávez González, González RodríguezE, Llanes Camacho MC, Garí Llanes M. Dispersión de la onda p en niños hipertensos, su relación con el peso corporal. CorSalud 2012 Oct-Dic;4(4):272-77.

27. Chávez González E, Castro Hevia J, González Rodríguez E, LLanes Camacho MC, et al. Incremento en la Dispersión de la Onda P Dependiente de la Tensión Arterial Media en Prehipertensos e Hipertensos. Relampa 2010; 23(2):75-81.

28. Chávez González E, González Rodríguez E, Castro Hevia J, LLanes Camacho MC, et al. Incremento en la dispersión de la onda $\mathrm{P}$ al disminuir el tiempo de eyección auricular en hipertensos y prehipertensos. Rev Colomb de Card 2011; 18(4):226-33.

29. Chávez E, González E, Castro J,Llanes MC, etal. Dispersión de la onda P dependiendo de la velocidad de la onda A del flujo de entrada mitral y de la tensión arterial sistólica. Rev Colomb de Card 2011; 18(1):59-64.

30. Martín García A, Jiménez-Candil J, Hernández J, Martín García A, et al. Morfología de la onda P y recurrencia tras cardioversión de fibrilación auricular aislada. Cartas científicas/Rev Esp Cardiol 2012;65(3):288-298.

31. Chávez E, González E, Castro J, Llanes MC, et al. Hipertensión arterial en población pediátrica, sus efectos en la dispersión de la onda $\mathrm{P}$ y el área auricular izquierda. Rev Chil Cardiol 2010; 29:322-32. 